\title{
Design of a Novel Semi-Automatic Coconut Tree Climbing Device
}

\author{
Yongfeng Liu', Jie Gong², Yanyun Lin², Fan Zhang², Hui Huang², Wen Xia², Yijun Liu², \\ Yunfei $\mathrm{Fu}^{2^{*}}$ \\ ${ }^{1}$ College of Mechanical Engineering, Liaoning Technical University, Fuxin, China \\ ${ }^{2}$ Agricultural Product Processing Research Institute at Chinese Academy of Tropical Agricultural Sciences, Chinese Agricultural \\ Ministry Key Laboratory of Tropical Crop Products Processing, Zhanjiang, China \\ Email: ^jackfuyunfei@hotmail.com
}

How to cite this paper: Liu, Y.F., Gong, J., Lin, Y.Y., Zhang, F., Huang, H., Xia, W., Liu, Y.J. and Fu, Y.F. (2018) Design of a Novel Semi-Automatic Coconut Tree Climbing Device. World Journal of Engineering and Technology, 6, 8-14. https://doi.org/10.4236/wjet.2018.63B002

Received: June 4, 2018

Accepted: August 6, 2018

Published: August 9, 2018

\begin{abstract}
The aim of this study is to present a novel semi-automatic coconut tree climbing device and validate its strength based on actual working conditions. Firstly, the structural composition and operational principal of this device is introduced. After that, the finite element model of this device is established with CATIA. Finally, the strength analysis is executed by means of CATIA. In this study, the equivalent stress, principal stress, and displacement contours are obtained. The simulation results show that the maximum stress of this device is below $355 \mathrm{MPa}$, which is the value of the yield strength. Therefore, this device is capable of satisfying practical application requirements.
\end{abstract}

\section{Keywords}

Agricultural Mechanization, Coconut Tree Climbing Device, Finite Element Method, Static Strength Analysis

\section{Introduction}

Hainan province is the only tropical island in China, which has abundant tropical agricultural resources. Specifically, coconuts are the typical tropical crop in Hainan, whose planting area is the third place among other corps. Presently, Hainan has 400 coconut processing factories, and more than 500 thousand people are related to the coconut processing industry. Undoubtedly, the coconut industry is the important backbone of Hainan.

However, the coconut tree is a kind of evergreen tree with the trunk of 15 to 30 meters height. In addition, coconut trees have fewer branches, so collecting coconuts is a technical difficulty for farmers. In recent years, some coconut tree 
climbing devices were developed by scholars from India and Thailand [1] [2] [3] [4], whereas China has few climbing machines until now [5]. Therefore, this paper aims to present a novel coconut tree climbing device for the farmers in China with the purpose of improving collecting efficiency and reducing working strength.

\section{Structural Composition}

This novel semi-automatic coconut tree climbing device mainly consists of the driving prod, driven prod, crossbeam, front beam, rear beam, backrest, fixed pulley, foot pedal, and driving case [6]. The structural composition of this machine is shown in Figure 1.

When climbing coconut trees, the front, rear, and cross beams are uninstalled first. Then, the device is fixed at the coconut tree. Afterwards, the front, rear, and cross beams are reinstalled. Particularly, the driven prod should be at the top left side of the coconut tree, and the driving prod should be at the bottom right side of the coconut tree. Climbers should stand on the foot pedal and their backs should be supported by the backrest. When climbers start the oil engine in the driving case, the driven prod will rotate with the driving prod via the belt such that the device can climb along the coconut tree. Interestingly, the collected coconuts can be transported to the ground by using the fixed pulley. After finishing the harvest, the riving prod will rotate oppositely such that climbers can move down to the ground.

\section{Establishment of Finite Element Model}

\subsection{Mesh Generation}

The 3D model of this device is meshed in CATIA with the tetrahedral mesh. In general, the finer the mesh is, the more accuracy the simulation result will be [7] [8]. Because of this, the element size is set as $10 \mathrm{~mm}$. The mesh model is shown

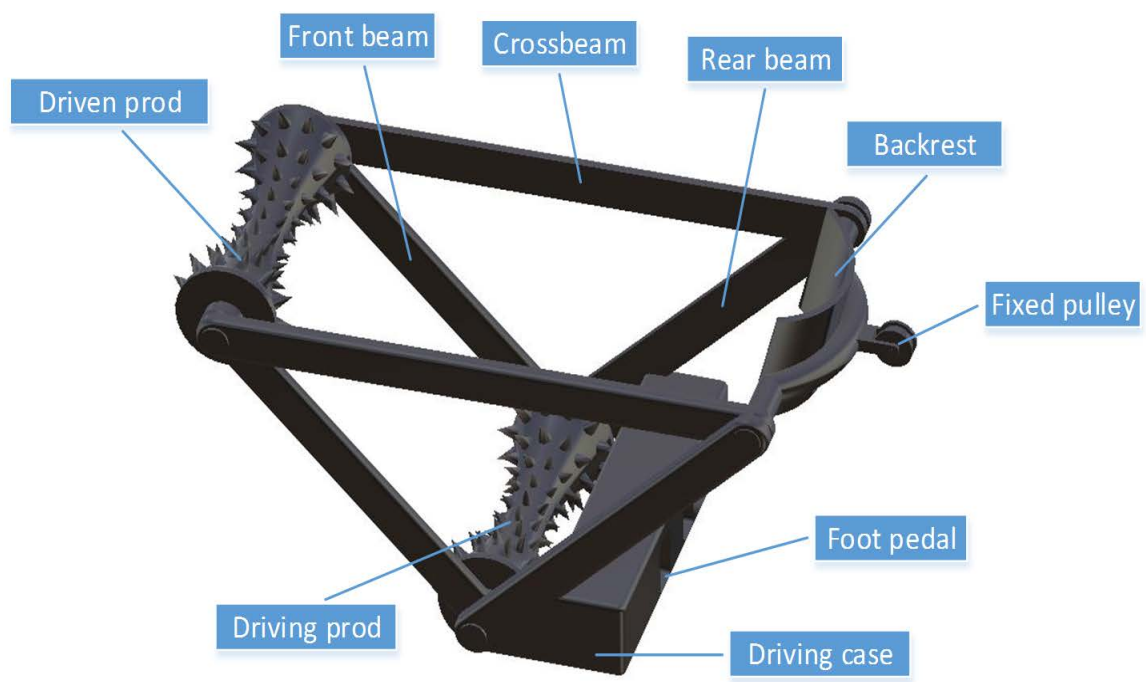

Figure 1. Structure diagram of semi-automatic coconut tree climbing device. 
in Figure 2. The number of elements is 4419, and that of nodes is 4322 .

\subsection{Material Properties}

The bi-linear kinematic hardening material model is utilized in this study. This model uses two segments to represent the elasticity and the stress-strain characteristics in the plastic stage. In addition, the slopes of these two segments denote the elastic modulus and tangent modulus, respectively. This material model is shown in Figure 3. In terms of this material model, the material is isotropic and irrelevant to the strain rate. The density, Yong's modulus, Poisson's ratio, and yield strength are used to define this material model.

The steel 45 is utilized in this paper, and its mechanical properties are shown in Table 1 .

\subsection{Boundary Conditions}

When the tree climber is working, the driven thorns are on the left side of the coconut tree, and the thorns are driven under the right side of the coconut tree. Two thorns separate the two sides of the trunk, one on top of the other, according to the two thorns and the coconut trunk. Forces can simulate the fixation of two sticks. The picker stands on the pedals with his feet on both feet and the back rests on the backrest. At the same time, when the entire machine and the picker are on top of the coconut tree and the coconut is fixed on one end of the rope, the total weight of the coconut and the picking will be fixed at the pulley.

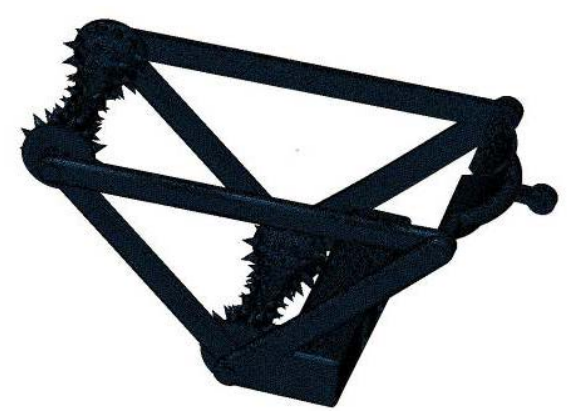

Figure 2. Mesh model.

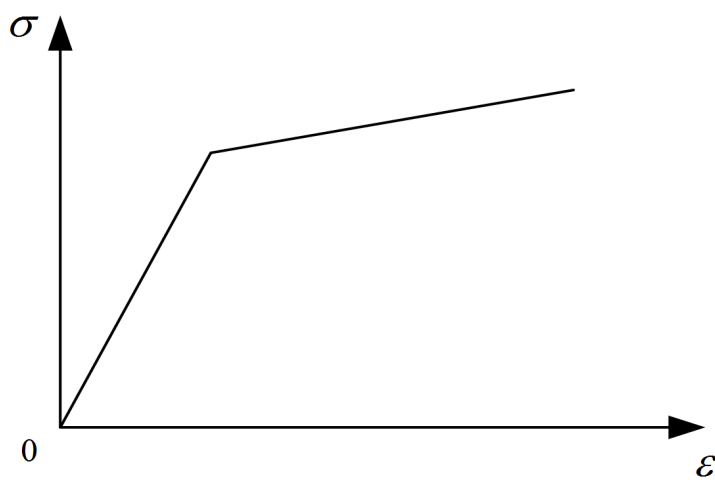

Figure 3. Bi-linear kinematic hardening material model. 
The force of the back of the person, at the same time, the force of the human gravity at the foot pedal and the gravity of the driving chassis. Based on the analysis above, fixed boundaries are applied on driving and driven prods, as shown in Figure 4.

The force points of this device concentrate on the fixed pulley and foot pedal. The selection of the weight of climbers is based on a little overweight people, $102.8 \mathrm{~kg}$. The total weight of coconuts of $70.7 \mathrm{~kg}$ is selected. Assume that the weight of the driving case is $180 \mathrm{~kg}$. The loadings are applied on the foot pedal and fixed pulley respectively, as illustrated in Figure 5.

\section{Analysis of Simulation Results}

The strength analysis in this study is executed with CATIA. The equivalent stress contour of this device is shown in Figure 6 . Figure 6 shows that the stress concentrations are mainly at three different positions. The maximum equivalent stress of this device is $165 \mathrm{MPa}$, which is less than the yield strength. This means this device will not break down during the collecting process.

Table 1. Mechanical properties of materials.

\begin{tabular}{ccc}
\hline Mechanical Properties & Values & Units \\
\hline Density & $7.85 \times 10^{-6}$ & $\mathrm{Kg} \mathrm{mm}^{-3}$ \\
Yong's modulus & 210 & $\mathrm{GPa}$ \\
Poisson's ratio & 0.31 & - \\
Yield strength & 355 & $\mathrm{MPa}$ \\
\hline
\end{tabular}

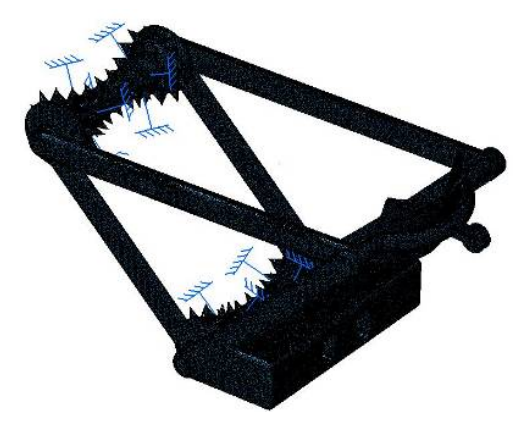

Figure 4. Position of constraints.

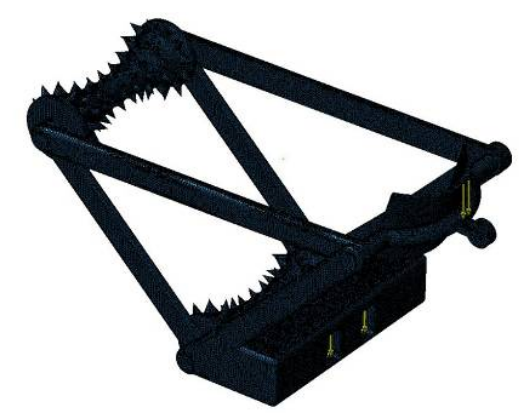

Figure 5. Position of loads. 


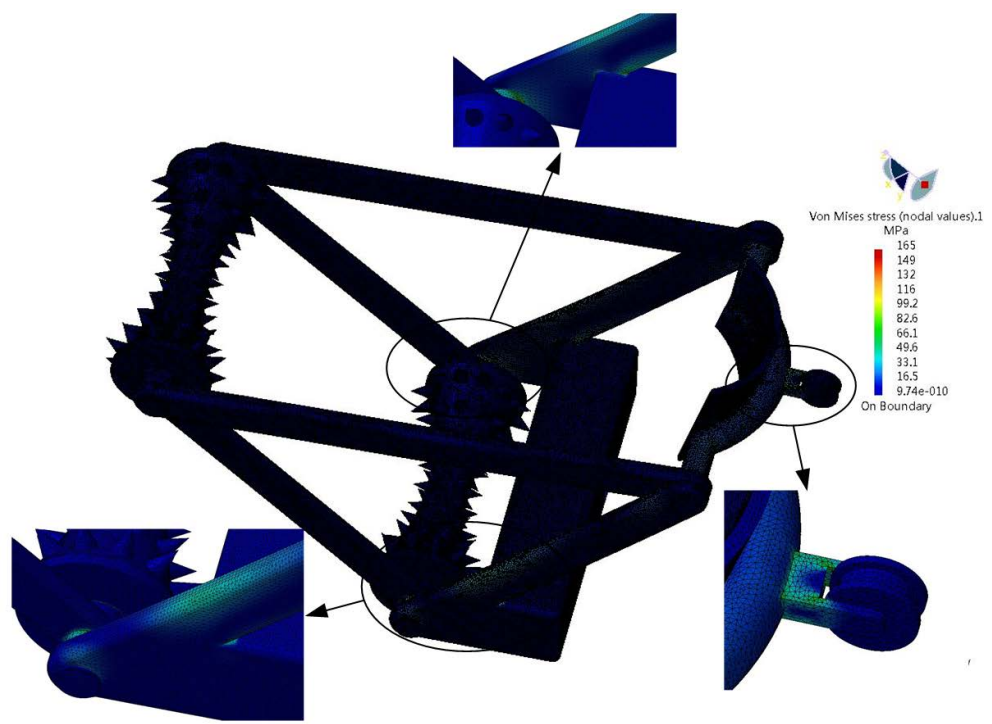

Figure 6. Equivalent stress contour.

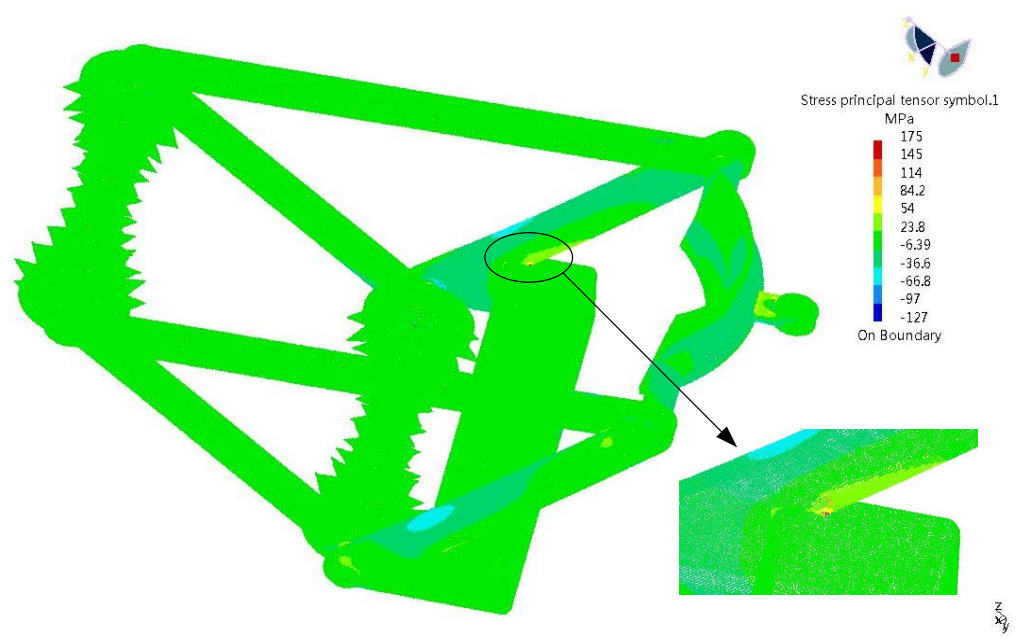

Figure 7. Principal stress contour.
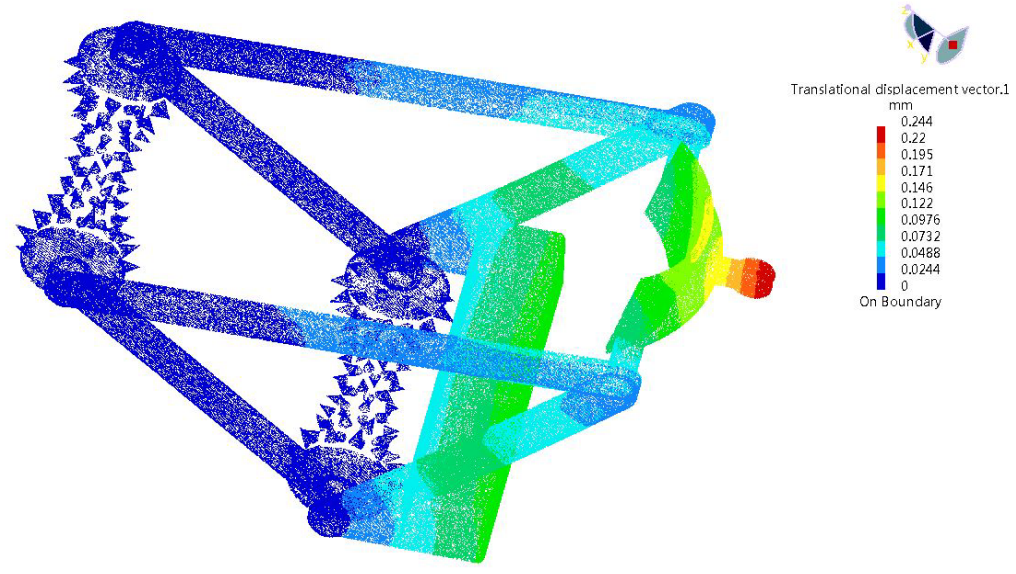

Figure 8. Displacement contour. 
The principal stress contour is shown in Figure 7. As shown in Figure 7, the maximum principal stress appears at the welded position between the rear beam and driving case, whose value is $175 \mathrm{MPa}$. Clearly, the maximum principle stress is less than the yield strength, $355 \mathrm{MPa}$, so this device is safe for coconut tree climbers.

The displacement contour of this device is shown in Figure 8. From Figure 8, the displacements of the rear beam, backrest and driving case are apparent. In particular, the displacement of the fixed pulley is the maximum, the value of which is $0.244 \mathrm{~mm}$. However, the displacement will not have negative impacts on the device. Therefore, this device is stale and reliable under the working condition.

\section{Conclusions}

1) The proposed semi-automatic coconut tree climbing device is of some advantages such as the simple structure, convenient operation, high efficiency, and reliable strength.

2) The strength of this device is able to satisfy practical application requirements because of having the maximum equivalent and principal stresses less than the yield strength of $355 \mathrm{MPa}$.

3) In our future work, a coconut tree climbing robot will be designed to improve the collecting efficiency of coconuts.

\section{Acknowledgements}

The research work was funded by the Hainan Natural Science Foundation (Project no. 517249).

\section{Conflicts of Interest}

The authors declare no conflicts of interest regarding the publication of this paper.

\section{References}

[1] Kolhe, K.P. (2009) Development and Testing of Tree Climbing and Harvesting Device for Mango and Coconut Trees. Indian Coconut Journal, 52, 15-20.

[2] Edacheri, D., Kumar, S. and Unakal, P. (2011) Design of a Coconut Tree Climbing Device. Sastech, 10, 87-94.

[3] Mohankumar, A.P., Krishnan, D.A. and Kathirvel, K. (2013) Development of Ergo Refined Coconut Tree Climbing Device. African Journal of Agricultural Research, 8, 5530-5537.

[4] Rajesh, M.K., Thejus, P., Allan, P., Trayesh, V. and Gokul, M. (2015) Robotic Arm Design for Coconut-Tree Climbing Robot. Applied Mechanics and Materials, 786, 328-333. https://doi.org/10.4028/www.scientific.net/AMM.786.328

[5] Fu, Y.F., Fan, H.K., Gong, J., Wei, X.Y., Lin, L.J., Li, J.H., Huang, H., Zhang, F., Liu, Y.J. and Xia, W. (2017) A Novel Tree Climbing Device. CN Patent No. ZL201621124809.6. 
[6] Gong, J., Liu, Y.F., Zhang, F., Huang, H. and Fu, Y.F. (2018) A Novel Semi-Automatic Coconut Tree Climbing Device. CN Patent No. 201820107244.3.

[7] Fu, Y.F., Gong, J., Li, P.W. and Yang, Z.M. (2017) Fatigue Life Assessment of Screw Blades in Screw Sand Washing Machine under Extreme Load. American Journal of Mechanical Engineering, 5, 1-7.

[8] Gong, J., Fu, Y.F., Xia, W., Li, J.H. and Zhang, F. (2016) Fatigue Life Prediction of Screw Blade in Screw Sand Washing Machine under Random Load with Gauss Distribution. American Journal of Engineering and Applied Sciences, 9, 1198-1212. https://doi.org/10.3844/ajeassp.2016.1198.1212 